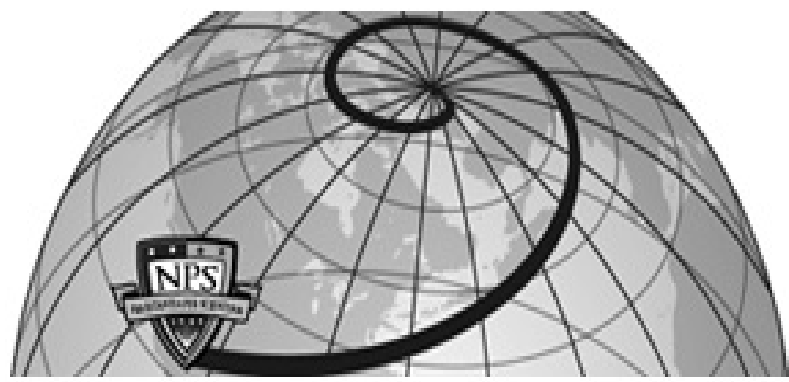

Calhoun: The NPS Institutional Archive DSpace Repository

\title{
Slowing down to keep the lead in military technology
}

Blanken, Leo J.; Leopore, Jason J.

Defence and Peace Economics, 2011, Volume 22, Issue 3, June, pp. 317-334

https://hdl.handle.net/10945/44479

This publication is a work of the U.S. Government as defined in Title 17, United States Code, Section 101. Copyright protection is not available for this work in the United States.

Downloaded from NPS Archive: Calhoun

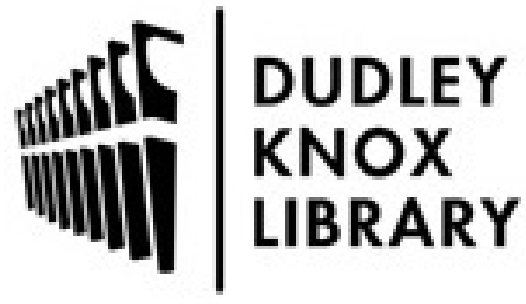

http://www.nps.edu/library
Calhoun is the Naval Postgraduate School's public access digital repository for research materials and institutional publications created by the NPS community. Calhoun is named for Professor of Mathematics Guy K. Calhoun, NPS's first appointed -- and published -- scholarly author.

Dudley Knox Library / Naval Postgraduate School 411 Dyer Road / 1 University Circle Monterey, California USA 93943 


\title{
SLOWING DOWN TO KEEP THE LEAD IN MILITARY TECHNOLOGY
}

\author{
LEO J. BLANKEN ${ }^{\mathrm{a}}$ AND JASON J. LEPORE ${ }^{\mathrm{b}, \dagger}$ \\ ${ }^{a}$ Department of Defense Analysis, Naval Postgraduate School, Monterey, CA, USA; ${ }^{b}$ Department of \\ Economics, Orfalea College of Business, California Polytechnic State University, San Luis \\ Obispo, CA, USA
}

(Received 11 August 2009; in final form 3 December 2009)

\begin{abstract}
We develop a model of military technology competition among states. States can choose to introduce new military technology, mimic rivals' level of technology, or withdraw from the contest. States can choose to implement any level of technology within their current feasible technologies. We find that states with significant technological leads should sometimes withhold new technologies, only strategically releasing them to trump rivals' efforts. We develop the model by refining Admiral Jackie Fisher's roughly articulated concept of 'plunging'. We then use this refined argument to reanalyze the case of naval rivalries among European powers between the Crimean War and the First World War. Finally, we conclude by discussing the model's implications for current US military force structure planning.
\end{abstract}

Keywords: technology diffusion; quolitative arms races; conventional force structure planning; weapons development JEL Classification: H56, Q38

\section{INTRODUCTION}

In $1905 \ldots$ the British Admiralty authorized the construction of HMS Dreadnought, a warship of revolutionary design that overnight seemed to render obsolete all existing battleships. Whether this decision was a 'fatal blunder' or a prescient anticipation ... is still being debated. (Lambert 1995: 595)

It is axiomatic that nation-states in an anarchic system are required to provide for their own security, and analyzing exactly how countries make these difficult choices constitutes the field of security studies. Within this literature there is a subset dedicated to qualitative competition among actors; concerning itself with how levels of technology are created and then diffused among actors (Evangelista, 1988; Goldman and Eliason, 2003; Paarlberg, 2004; Rosen, 1984). This literature on military technology commonly assumes, explicitly or implicitly, that each actor strives to stretch the boundaries of technology and to field the most technologically advanced forces possible - constrained only by budget (Schilling, Hammond and Snyder, 1962) or arms-control agreement (Goldman, 1994; Schelling and Halperin, 1985). ${ }^{1} \mathrm{We}$

\footnotetext{
$\dagger$ Corresponding author: Department of Economics, Orfalea College of Business, California Polytechnic State University, San Luis Obispo, CA 93407, USA. Email: jlepore@ calpoly.edu

${ }^{1}$ An interesting exception is a recent analysis of the United States military by Arquilla (2008).
} 
problematize that assumption by assessing whether actors may be able to strategically withhold new technological developments to their advantage.

Pre-First World War British naval supremacy provides a compelling case to consider. In the second half of the 'long' nineteenth century, naval technology was changing at a rapid pace. Britain, the greatest naval power of the era, was fretting over maintaining its lead over rising challengers, namely France, Russia, and Germany. This period provides a classic example of a qualitative, as well as quantitative, arms race among rival powers and allows us to discern how a technological lead can be managed.

A key participant in this competition, the colorful British Admiral Sir Jackie Fisher, suggested the kernel of a prescriptive theory he referred to as 'plunging'. This is the parceling out of technological innovations to preempt rivals and, thereby, maximize the leverage a technological lead may provide. We expand upon and formalize Fisher's rough writings to flesh out a more complete theory of plunging. We then use the model to shed light upon debates over Britain's naval policy vis-à-vis its rivals in the decades before the First World War.

To do so we develop a model of military technology competition among nation-states. Each actor can choose to introduce new military technology, mimic its rival's level of technology, or withdraw from the contest. Actors can choose to implement any level of technology within their current feasible technologies. We find that actors with significant technological leads should, under specified conditions, withhold technologies and only strategically release them to trump rival's efforts. For a leading actor, increasing its technological implementation level has two countervailing effects: (1) it increases its short-run payoff by way of increasing bargaining power in a time of peace and military power in a time of war; and (2) it decreases the actor's future payoff by narrowing its future advantage in technology. Thus, the choice to plunge is optimal when the second, indirect, effect is strong enough to overpower the first effect. At the extreme, if an actor has a sufficient lead and is sufficiently patient, it will want to make the minimal progress to keep its rival mimicking.

The paper proceeds as follows. In the next section we explore the writings of Sir Jackie Fisher on weapons technology and develop the intuition behind our argument. We then propose a formal model of the strategic management of technology - refining Fisher's concept into two component parts: 'positive plunging' (implementing better technology than a rival); and 'negative plunging' (the withholding of technology). In the fourth section we return to the British case and show how the refined model of plunging helps to re-interpret naval policy choices. Finally we offer some general conclusions, relate our model to a recent policy debate, and propose directions for future research.

\section{BRITISH NAVAL POLICY, JACKIE FISHER, AND THE CONCEPT OF PLUNGING}

Naval technology changed more in the second half of the nineteenth century than it had in the previous 10 centuries (Marder, 1976: 4). Ships changed from wooden-hulled, sail-powered platforms carrying smooth-bored, muzzle-loading cannon that fired solid shot to compartmentalized steel-hulled, turbine-driven platforms carrying rifle-bored, breech-loading guns that fired high-explosive munitions (Brodie, 1943; 1976). The increasing rate of technological change can be illustrated by the fact that Admiral Nelson's flagship at the battle of Trafalgar (1805), HMS Victory (3,500 tons displacement) had been in service since 1765 and was still considered to be a modern vessel. By the end of the nineteenth century, however, ships that were still under construction ran the risk of being made obsolete before they were launched prompting Gladstone's famous complaint that battleship design changed as quickly as the fashion of ladies' hats (Sondhaus, 2001: 161); this evolution culminated in such ships as HMS 
Dreadnought (launched 1906, 18,420 tons displacement) and HMS Lion (launched 1910, 26,250 tons displacement). ${ }^{2}$ Adding perplexity to the situation were technical developments in the areas of sea mines, torpedoes, and submarines - each of which presented new threats and challenges to naval strategy and shipbuilding policy.

\section{The British Position}

Britain ruled the waves during the period between the Crimean War and the First World War, but its maritime preeminence was the result of massive investment and carefully crafted policy. Naval supremacy was regarded as of paramount concern to the island nation as it relied on imported commodities and was responsible for a global empire. Britain needed to manage its maritime lead along two dimensions: quantitative and qualitative. In terms of quantity, Britain's pace of capital ship building was encoded in the 'two power standard' (roughly laying two keels to one against the second and third naval powers combined), but the management of the qualitative lead was more difficult and policy was less clear. To explicate the British management of its technological lead we discuss it in two parts: Britain's concern with 'leveling the playing field' with competitors; and Admiral Fisher's loose conception of plunging as a prescription for British policy. In doing these tasks we distill an argument for a formal theory of plunging that will be developed in the following sections of the paper.

One chief concern for British policymakers during this period of rapid technological change was the leveling of the playing field vis-à-vis its rivals. This would be devastating to Britain's naval supremacy as a revolutionary technology could cause Britain and its rivals to all start afresh on even terms. Two technologies, in particular, seemed to threaten as levelers: Dreadnoughts and the combination of submarines and torpedoes. Fisher's push for new technologies, including the Dreadnought, often made him the target of these accusations of leveling: ${ }^{3}$

Fisher's critics derided the dreadnought policy chiefly on the ground that it rendered all existing battleships obsolete, so sweeping away Britain's overwhelming preponderance in battleships (about three to one over Germany) and giving the Germans a level, or nearly level, start in the competition for naval supremacy. Fisher never denied that the introduction of the Dreadnought was tantamount to starting de novo. (Marder, 1956: 25)

Fisher, then, was aware of these risks, but felt that innovation was inevitable, writing to Winston Churchill in 1912 that '[t]he luxuries of the present are the necessities of the future' (Marder, 1956: 426). The key for Fisher was to utilize technological change as a leveraging tool in Britain's naval supremacy, not as a specter to be feared. It is his ruminations on leveraging technological leads through plunging which provides the basis for our argument.

\section{Fisher's Vision of Plunging}

Fisher's career in the Admiralty was characterized by his focus on emerging technology and its impact on Britain's naval strategy and, hence, overall national security. Aware of the dangers of new technology to Britain's preeminent status, but also aware of the inevitability of technological progress, Fisher developed the concept of plunging as a strategy to leverage Britain's lead over emerging rivals (Lambert, 2004: 279-281). Fisher summed up the concept in a 1912 letter to Churchill:

\footnotetext{
${ }^{2}$ Stoll (1992) argues more specifically that there were two periods of rapid innovation (1860-1880, 1906-1914) separated by a span of relative stability (1880-1906).

${ }^{3}$ Recent research has shown that Fisher's first choice was the all-big gun 'battle cruiser' rather than the dreadnought battleship (Sumida, 1995), but this distinction is moot in the context of the current discussion.
} 
THE GREAT SECRET IS TO PUT OFF TO THE VERY LAST HOUR THE SHIP (big or little) that you mean to build (OR PERHAPS NOT BUILD HER AT ALL!). You see all the rivals' plans fully developed, their vessels started beyond recall, and then in each individual answer to each such rival vessel you plunge with a design 50 percent better! knowing that your rapid shipbuilding and command of money will enable you to have your vessel fit to fight as soon if not sooner than the rival vessel. (Marder, 1956: 431, emphases in original)

This elucidates one crucial aspect of Fisher's vision - using technological leads strategically to trump rivals' efforts. The effect is maximized when you time your plunge to waste a rival's time and unrecoverable resources on weapons systems that are to be made obsolete. This active usage of technological leads is what we term positive plunging.

Crucial for this strategy to work was not pushing the envelope beyond what was required to trump rivals' efforts - as doing so ran the risk of diffusing valuable technology to your opponent. This reticence to diffuse technology drives what we term the negative aspect of the plunging policy - withholding technological advances that cannot yet be leveraged strategically. This negative aspect of plunging remains implicit in Fisher's writings; our model, however, shows how the deleterious impact of technology diffusion conditions the choices of actors.

Given this analysis of turn-of-the-century British naval policy and the rough writings of Jackie Fisher, we now generate a model of leveraging technological leads. These include: the ability to implement a force structure that does not utilize your highest level of technology; the ability to mimic rivals' technology; and takes into account the speed with which you can field new units, all of which is done under the shadow of war. ${ }^{4}$ After the analysis of the model, we return to the British case to assess whether our refined argument sheds new light on strategic choices made at that time.

\section{FORMAL MODEL}

The model we construct highlights what we have termed 'negative' plunging. That is, our refined argument concerning strategic withholding implementation of advanced technological capabilities. $^{5}$

The model is a repeated game of two actors, denoted by $i \in\{1,2\}$, choosing to invest in military technological capacity (capacity), then choosing what level of technology to implement (level). ${ }^{6}$ The game is one of complete information. ${ }^{7}$ Denote by $\mathrm{s}_{\mathrm{t}}^{\mathrm{i}} \geq \mathrm{C}$ technology implementation level of each actor $i \in\{1,2\}$, at period $t$. Each actor has an identical technological capacity production function $f(x)=\alpha x$, with $\alpha>1$. Denote by $\mathrm{x}_{\mathrm{t}}^{\mathrm{i}} \geq($ actor $i$ 's technological capacity in period $t$. Given the capacities of last period $\left(\mathrm{x}_{\mathrm{t}-1}^{1}, \mathrm{x}_{\mathrm{t}-1}^{2}\right.$, an actor can choose to invest in technology innovation and get $\alpha \mathrm{x}_{\mathrm{t}}^{\mathrm{i}}$ as its capacity next period, or invest in technological

\footnotetext{
${ }^{4}$ In this model, war occurs exogenously. We find this simplification allows us to highlight the impact of technology on security planning. Future extensions of the model might fruitfully explore the impact of an endogenous choice for war by the actors.

${ }^{5}$ We focus on 'negative' plunging because, in equilibrium, we find that actors always choose to engage in 'positive' plunging. This is intuitive in the context of our argument; given the choice, actors never choose to implement technology which is inferior to their rivals.

${ }^{6}$ The model can be extended to $I \geq 2$ actors. As a result, however, analysis of the equilibria becomes much more complex and notation intensive. We find the two-actor model does not lose any important insights from the more general model, while providing a considerable gain in clarity.

${ }^{7}$ In the scenario we are modeling, there is obviously incomplete information. We are able to model this phenomenon without incomplete information, because, although we assume that each actor $i$ knows everything about the other's history, they are limited in what they can replicate. For this reason, assuming complete information does not perversely affect the equilibria of the model.
} 
imitation of the other actor's last period level: $\mathrm{s}_{\mathrm{t}-1 .}^{\mathrm{j}}{ }^{8}$ If an actor chooses to invest in innovation, its capacity for the next period is $\alpha \mathrm{x}_{\mathrm{t}}^{\mathrm{i}}=\mathrm{x}_{\mathrm{t}+\mathrm{t}}^{\mathrm{i}}$. But it is free to implement any level $\mathrm{s}_{\mathrm{t}+1}^{\mathrm{j}}$ such that $\mathrm{s}_{\mathrm{t}+1}^{\mathrm{i}} \leq \mathrm{x}_{\mathrm{t}+\text {. }}^{\mathrm{i}}$

The expected payoff of each actor depends on an uncertain state of the world, which we will refer to as 'possibilities'. For simplicity, we assume two possibilities: war and peace. Denote by $\mu$, the probability of war and $(1-\mu)$ the probability of peace such that $\mu \in(0,1)$. The distribution is assumed to be independent and identical each period. ${ }^{9}$

In peacetime, the implemented technology level affects the bargaining power of the two actors. Thus, we define the expected payoff in peacetime for actor $i$ by $P^{i}(s)$, where $s=\left(s^{1}, s^{2}\right)$. In wartime the visible technology is important, but so is the hidden technological capacity; production of that technology could ensue and at least some of the hidden technology could be utilized. Thus, we define the expected payoff in wartime, for actor $i$ by $W^{i}(s, x)$, where $x=$ $\left(x^{1}, x^{2}\right)$.

The following assumptions specify the basic properties of each actor's possible single period payoff.

Assumption 1 The peaceful payoff has the following attributes: The function $P^{i}(s)$ is strictly concave and twice-continuously differentiable in $s$ on $\mathfrak{R}^{2} . P^{i}(s)$ is increasing in $s^{i}$ and decreasing in $s^{j}$. Further, for all $s \in \mathfrak{R}^{2}$, there exists a finite $\gamma^{P}>0$ such that $P^{i}(s)<\gamma^{P}$.

This assumption encompasses the fact that the expected payoff from peace to actor $i$ is increasing in its own technological level, while decreasing in its rival's. This reflects the additional bargaining power in peacetime negotiations leveraged from an increased technological level. In addition, the assumption reflects diminishing marginal returns to an actor's technological level.

Assumption 2 The wartime payoff has the following attributes: the function $W^{i}(s, x)$ is strictly concave and twice-continuously differentiable in $s$ and $x$ on $\mathfrak{R}^{4} . W^{i}$ $(s, x)$ is increasing in $s^{i}$ and $x^{i}$, and decreasing in $s^{j}$ and $x^{j}$. Further, for all $(s, x)$ $\in \mathfrak{R}^{4}$, there exists a finite $\gamma^{W}>0$ such that $W^{i}(s, x)<\gamma^{W}$.

This assumption captures the feature that the expected payoff from war to actor $i$ is increasing in its own technological level and capacity, while decreasing in its rival's. This reflects the increased probability of war success that accompanies increased technology.

Assumption 3 For all $(\mathrm{s}, \mathrm{x}) \in \mathfrak{R}^{4}, \partial^{2} \mathrm{~W}^{\mathrm{i}}(\mathrm{s}, \mathrm{x}) / \partial \mathrm{s}^{\mathrm{i}} \partial \mathrm{x}^{\mathrm{j}}=0$.

This final assumption is that a rival's technological capacity does not impact the marginal impact of an agent's technological level on their war-time payoff.

The expected payoff of actor $i$ of period $t$ is denoted by:

\footnotetext{
${ }^{8}$ We omit the choice to not invest in any technology improvement on the basis that the game is essentially a prisoner's dilemma and not investing is a strictly dominated strategy. This assumption adds considerable parsimony to the analysis without impacting the result.

${ }^{9}$ The assumption of binary extreme states, war and peace, is clearly a gross oversimplification of the conflict scenarios a country can face. The specific binary assumption is not important for the plunging result; we could instead assume a whole continuum of states between war and peace, but notation and formalization of the model would become rather cumbersome. The key feature that drives our results is that in some states of nature capacity is important, while in others it is not.
} 


$$
\pi^{\mathrm{i}}\left(\mathrm{s}_{\mathrm{t}}, \mathrm{x}_{\mathrm{t}}\right)=\mu \mathrm{W}^{\mathrm{i}}\left(\mathrm{s}_{\mathrm{t}}, \mathrm{x}_{\mathrm{t}}\right)+(1-\mu) \mathrm{P}^{\mathrm{i}}\left(\mathrm{s}_{\mathrm{t}}\right)
$$

In the interest of parsimony, we assume that each actor has a common discount factor $\delta \in$ $(0,1)$. We now move to analysis of equilibrium behavior in our model.

\section{Equilibrium}

We focus on Markov perfect equilibrium of our game; that is, equilibrium strategies that only depend on the most recent choices. In accord with our equilibrium concept, we focus on Markov strategies in levels based only on the current capacity choices and Markov strategies in capacities based on the previous period capacities and levels. Next we define our equilibrium concept.

Definition 1 A Sequential Markov Perfect Equilibrium (SMPE) is the possibility based strategies $\hat{s}(x)$ and $\left(\hat{x}^{1}\left(x^{1}, s^{2}\right), \hat{x}^{2}\left(x^{2}, s^{1}\right)\right)$ for all $s$ and $x$ such that, $\forall i \in\{1,2\}$

$$
\begin{gathered}
\hat{s}^{i}\left(x_{t}\right) \in \underset{s^{i} \in\left[0, x_{t}^{i}\right]}{\operatorname{argmax}}\left\{\pi^{i}\left(s^{i}, \hat{s}^{j}\left(x_{t}\right), x_{t}\right)+\sum_{s=t+1}^{\infty} \delta^{s} \pi^{i}\left(\hat{s}_{t}, \hat{x}_{t}\right)\right\}, \\
\hat{x}^{i}\left(s_{t-1}^{j}, x_{t-1}^{i}\right) \in \underset{x^{i} \in\left[0, \max \left\{\alpha x_{t-1}^{i}, s_{t-1}^{j}\right\}\right]}{\operatorname{argmax}}\left\{\pi^{i}\left(\hat{s}_{t}, x^{i}, \hat{x}_{t}^{j}\right)+\sum_{s=t+1}^{\infty} \delta^{s} \pi^{i}\left(\hat{s}_{t}, \hat{x}_{t}\right)\right\} .
\end{gathered}
$$

The key to our ensuing analysis of technological levels is a reduction in the dimensionality of the strategies we must analyze. In particular, we are interested in SMPE where both actors always maximize technological capacity. These are equilibria such that each actor chooses technological capacity according to the following rule $(\dagger)$.

For all $i \in\{1,2\}$ and $j \neq i$,

$$
\dagger \quad \hat{x}_{t}^{i}\left(s_{t-1}^{j}, x_{t-1}^{i}\right)=\left\{\begin{array}{lll}
\alpha x_{t-1}^{i} & \forall \alpha x_{t-1}^{i} & \geq s_{t-1}^{j} \\
s_{t-1}^{j} & \forall \alpha x_{t-1}^{i} & \leq s_{t-1}^{j}
\end{array} .\right.
$$

Let us, for now, impose capacity choices following $(\dagger)$ into our model and analyze the equilibrium strategies in levels. In the formal analysis we show capacity play according to $(\dagger)$ is part of our unique equilibrium.

Since we focus on maximum capacity strategies we can write the expected payoff of actor $i$ as a function of the current capacity $x t$ and the current choice $s t$ and, under the supposition that an a SMPE exists, strategies for time $t+1: \hat{s}\left(x_{t+1}\right)$ for all integers $t \geq 1$. Hence, we can express the equilibrium expected payoff of actor $i$ purely as a function of $x_{t}$ and $s_{t}$. Define recursively the equilibrium expected payoff in $x_{t}$,

$$
V^{i}\left(x_{t}\right)=\max _{s^{i} \in\left[0, x_{t}^{i}\right]}\left\{\pi^{i}\left(s^{i}, \hat{s}^{j}\left(x_{t}\right), x_{t}\right)+\delta V^{i}\left(x_{t+1}\right)\right\} .
$$

It is useful to first study optimal Markov strategies of an actor informally; this is best done broken into two cases. Case 1 is when both actors are similar enough in technology such that they both choose to innovate in period $t$.

\section{Case 1}

Let us suppose that $\alpha \mathrm{x}_{\mathrm{t}-1}^{\mathrm{i}} \geq \mathrm{s}_{\mathrm{t}-}^{\mathrm{j}}$ for $i \in\{1,2\}$. Rule $(\dagger)$ implies that, for both actors, $\mathrm{x}_{\mathrm{t}}^{\mathrm{i}}=\alpha \mathrm{x}_{\mathrm{t}-1}^{\mathrm{j}}$ 
An actor's optimal Markov action is to choose $s_{t}^{i}$ to maximize its expected payoff subject to the constraint that $\mathrm{s}_{\mathrm{t}}^{\mathrm{i}} \leq \mathrm{x}$. Since neither actor imitated this period, at maximal capacities and levels no actor will imitate in the future. This implies that $s_{t}^{i}$ cannot impact the future strategy of actor $j$. Therefore, $s_{t}^{i}$ will be picked to maximize the current payoff $\pi^{i}\left(s_{t}, x_{t}\right)$. The expected payoff of actor $i$ for period $t$ is strictly increasing in actor $i$ 's technological level based on the increase in bargaining power it provides in times of peace and the increased probability of succeeding in times of war. Thus, the payoff will be maximized at the highest available technological level and actor $i$ maximizes its payoff by way of implementing $\mathrm{s}_{\mathrm{t}}^{\mathrm{i}}=\mathrm{x}_{\mathrm{t}}^{\mathrm{i}}$. This must be true for both actors $i \in\{1,2\}$. Therefore, if an equilibrium exists, it must be such that $s_{t}=x_{t}$ if $\alpha \mathrm{x}_{\mathrm{t}-1}^{\mathrm{i}} \geq \mathrm{s}_{\mathrm{t}-}^{\mathrm{j}}$ for $i \in\{1,2\}$.

Consider a second case where one actor has a sufficient lead to induce the other actor to imitate.

\section{Case 2}

Consider the case that $\alpha \mathrm{x}_{\mathrm{t}-1}^{2}<\mathrm{s}_{\mathrm{t}-1}^{1}$, where without loss of generality we focus on the case that actor 1 is in the technological lead.

Following the same lines as Case 1, we know that it is optimal for actor 2 to choose $s_{t}^{2}=x_{t}^{2}$. That is, actor 2 will gain on the margin by increasing their technological level for all levels up to their capacity (since actor 1 will never imitate).

Now, let us consider the choice of actor 1. In contrast to Case 1, the future payoff of actor 1 is impacted by their choice of implementation level in two ways. The first is directly through their period $t$ expected payoff (the same as in Case 1). This is what we label the direct effect on their current expected payoff. The second is indirect through the influence on actor 2's future technological capacity. We call this the indirect imitation effect on their future expected payoff. The two effects impact the payoff of actor 1 in opposing ways. An increase in $s_{t}^{1}:(1)$ increases the period $t$ payoff through peaceful bargaining power and increased chances of winning a war; and (2) decreases actor 1's future expected payoff through increasing the future technological capacity and level of actor 2 .

The optimal choice of $s_{t}^{1}$ will depend on the relative magnitude of these two effects. If the direct effect dominates, then actor 1's payoff is maximized implementing technology up to their capacity. If the indirect imitation effect is strong enough, then implementation of technology below capacity is optimal. This second case is what we have identified as negative plunging.

The following theorem provides a characterization of the SMPE that we have described informally. In the characterization we drop the time subscripts as they are unnecessary since strategies are only state dependent. Denote by $\hat{s}^{i}(x)$ the optimal action of actor $i$ given the state $x$.

Theorem 1 Under assumptions $1-3,{ }^{10}$ there exists a unique SMPE characterized as follows:

- For all $x$ such that $x^{i} \leq \alpha x^{j} \Rightarrow \hat{s}^{i}(x)=x^{i}$;

- For all $x$ such that $x^{i}>\alpha x^{j}$, there exists $\underline{\delta}(x)$ and $\bar{\delta}(x)$ in $(0,1)$ such that

$$
\hat{s}^{i}(x) \in\left\{\begin{array}{cc}
\alpha x^{j} & \forall \delta \in[\bar{\delta}(x), 1) \\
\left(\alpha x^{j}, x^{i}\right) & \forall \delta \in(\underline{\delta}(x), \bar{\delta}(x)) . \\
x^{i} & \forall \delta \in(0, \underline{\delta}(x)]
\end{array}\right.
$$

\footnotetext{
${ }^{10}$ Assumption 3 is only used to guarantee global uniqueness of the SMPE. Under only Assumptions 1 and 2, the characterization of the equilibrium is unaffected, but we can only establish that the play described by the theorem is the unique SMPE such that capacities follow $(\dagger)$.
} 


\section{- Equilibrium capacity choices follow (†).}

The formal proof of this result is relegated to the Appendix. The key factor that induces negative plunging (withholding technological capacity) is that the indirect effect weighs strongly enough to make the marginal effect of an increase in level negative at full capacity implementation. Since the expected payoff of actor $i$ is strictly concave in its current technological level, a decrease in level away from capacity will increase actor $i$ 's payoff.

Outside the scope of the formal theorem we can address some underlying comparative statics of potential interest. It should be quite obvious that the parameters of the model dictate the choice to plunge or not. A primary implication of Theorem 1 is that the greater the patience of actor $i$, ceteris paribus, the more actor $i$ is willing to engage in negative plunging. This is because increased patience puts more weight on the actor's future payoff, which is decreasing in their current technological level. This is formally stated in the following theorem.

Theorem 2 For all $x$ such that $x^{i}>\alpha x^{j}, \hat{s}^{i}(x)$ is non-increasing in the parameter $\delta \in$ $(\underline{\delta}(x), \bar{\delta}(x))$.

An alternative interpretation of an increase in $\delta$ is that the time period for technological progress is shortened; that is, technology is able to change more rapidly and technological decisions happen more frequently. This relates to our next result.

The parameter $\alpha$ represents the exogenous maximal rate of technological innovation. The greater the maximal rate of technological progress, ceteris paribus, the more severe negative plunging will become. This is because negative plunging can create a larger gap in the future technologies. Thus, the future benefit of withholding technology becomes greater.

Theorem 3 For all $x$ such that $x^{i}>\alpha x^{j}$, and $\delta \in(\underline{\delta}(x), \bar{\delta}(x)), \hat{s}^{i}(x)$ is non-increasing in the parameter $\alpha$.

Another important factor is the marginal sensitivity of the war payoff to changes in technological capacity; the more sensitive the war payoff is to changes in capacity, the lower the critical discount factor for negative plunging $(\underline{\delta}(x))$. Assume that the marginal change in the war payoff of agent $i$ in terms of agent $j$ 's capacity is constant. Formally, $\partial W^{i} / \partial x^{j}=-\gamma$, where $\gamma>0$.

Theorem 4 For all $x$ such that $x^{i}>\alpha x^{j}$, and $\left.\delta \in(\underline{\delta}(x)), \bar{\delta}(x)\right), \hat{s}^{i}(x)$ is non-increasing in the parameter $\gamma$.

It is worth noting that it is not entirely clear that a greater lead in technological capacity is more likely to lead to negative plunging. This is because, while the greater disparity in technology can decrease the marginal impact of current levels on country 1's future payoff, it also increases the marginal impact of current levels on 1's current payoff. This highlights the impact of the threat environment on strategic choice over technological levels in and of themselves.

The impact of these factors is an important aspect of the model. It not only shows the sensitivity of force structure planning to the international context, it specifies how changes in military technology, current force structure, and threat perception should impact the strategic choice of actors. Returning to the British case, we can reevaluate some of the strategic choices of the Admiralty in a new light.

\section{WAS 'PLUNGING’ EMPLOYED BY BRITAIN?}

To what degree was a plunging strategy actually employed by the British navy? There is little evidence that this was a coherent or consistent policy, but there is some evidence to suggest 
that the notion of strategically managing its technological lead was, to some degree, employed as our model predicts. Further, our refinement of Fisher's rough ideas into distinct 'positive plunging' and 'negative plunging' components provides new insights into the trajectory of British naval policy from the Crimean War to the First World War. We argue that from 1856 to 1898 the British were patient and felt that the war payoff was relatively more sensitive to unimplemented technological capacity. These parameter values increase the value of negative plunging (withholding technological leads) as well as positive plunging; we observe this in British naval policy. From the turn of the century until the outbreak of the First World War, however, England engaged in a heated rivalry with Germany. The changing parameter values associated with this second period make withholding technology capacity less beneficial; British policy changed accordingly to employ only positive plunging.

\section{Britain without a Peer Competitor, 1856-1898}

The first period we consider spans 1856-1898. This is characterized for the British by a relatively low-threat environment, as Britain was not challenged by a peer competitor in its naval supremacy. This not only resulted in Britain being patient, but also confident in its ability to utilize its technological lead with celerity should war occur. We find that, as predicted by the model, Britain engaged in both the positive and negative aspects of plunging in this period: strategically trumping rivals' technological advances, but also refraining from superfluous technology diffusion by implementing below their full capacity.

Consider the following summary of the period: 'The British Navy was ... conservative in its designs, preferring to let other navies innovate, and then to use its greatly superior resources (including the ability to build ships more quickly than other navies) when other experiments were shown to be successful. (Stoll, 1992: 268). Morris adds that these British warships which were 'built in response to foreign initiatives' were also 'themselves full of new ideas. They were seldom built as classes, but were generally only in ones and twos ... they were sample ships' (1995: 90). Admiral Fisher's writings support this attitude: 'whatever type the French have, we must go one better, and that is a principle which will always keep us safe, and, if we built as quickly as we ought to build, we ought always to commence after they are well advanced and have the more powerful vessel afloat beforehand' (Marder, 1952: 174). This shows the model's predictions being born out in Britain's surface fleet: confidence in shipbuilding speed and general patience allowed Britain to strategically parse out its technological capacity. It was implementing ahead of its rivals, but only when forced to do so.

Besides surface ships, the late nineteenth century also saw the development of submarine craft, which would have an increasing impact on naval warfare. The policy regarding submarine ships provides a clear case of the negative aspect of plunging. A memorandum by the Navy Controller Sir Arthur Wilson in January of 1901 provides a telling summary of Britian's submarine policy in the 1856-1898 period and is worth quoting at length:

\footnotetext{
We cannot stop invention in this direction [submarine warfare], but we can avoid doing anything to encourage it. [We successfully] delayed the introduction of submarine mines for half a century ... [and t] he question of submarine boats is taking a very similar course. A very well thought out design for a submarine boat was brought to my notice ... about 1879 ... Experiments were carried out which proved the practibility ... [and then] the inventor was given no further encouragement. A very similar course has been adopted with all the various submarine boats that have been brought forward since. Each design has been carefully examined and ... then it has been quietly dropped with the result of delaying the development of the submarine boat for about 20 years. (Lambert, 2001: 20)
}

Britain's policy towards submarines in this period was quite clearly, then, to withhold technological capacity to prevent its diffusion. 
There are several important points embedded in the evidence from this period. The first is the fact that, due to a lack of peer competitor pressure, Britain could refrain from innovation and merely respond to foreign challenges by trumping rivals efforts through rapid counterdevelopments (encompassing both the positive and negative aspects of plunging). The second is the fact that Britain could rely on its industrial base to rapidly implement new ship technology; this is an example of marginal sensitivity of excess capacity on wartime payoffs, as Britain could rapidly implement hidden technology if war were to occur. These parameter values predict both positive plunging, which we observe clearly in Britain's surface ships, and negative plunging, which we observe both in Britain's surface ships and submarine warfare policy.

\section{Britain's Growing Rivalry with Germany, 1898-1914}

By the turn of the century Britain's security in its naval supremacy was beginning to diminish as Germany began a bid for significantly increased influence, if not hegemony, in Europe. This can be traced back to Germany's Navy Laws of 1898 and 1900 which signaled an aggressive expansion in naval capabilities (Steinberg, 1971; Marder, 1956: 22; Sumida, 1990: 17). Admiral Fisher himself was so fixated on the rising menace that in a letter to Whitehall in April 1905 he implored the foreign ministry to engineer a war with Germany: 'this seems a golden opportunity for fighting the Germans in alliance with the French, so I earnestly hope you may be able to bring this about' (Marder, 1956: 55).

Not only did the rise of Germany, along with the solidification of the Triple Alliance and the Triple Entente, increase the threat environment for Britain in the first decade of the twentieth century, but increasing competition by late-industrializers made Britain less secure in future competition.

Further, the nature of Germany's technical capacity made Britain rethink the marginal sensitivity of excess capacity on wartime payoffs. Underinvestment in Britain's industrial base was leading to its being surpassed in shipbuilding capacity by Germany (Robertson, 1974). Stoll argues that this changing parameter value was 'prominent in the minds of British policymakers:

consider the British situation when the focus of British naval concern shifted from France and Russia to Germany ... one additional factor enters into British calculations; the speed of German naval construction approached that of the British, so part of the cushion of British safety disappeared. (Stoll, 1992: 271-272)

Given these changing parameter values, then, the model predicts a continued policy of positive plunging (staying ahead of rivals), but no longer one of negative plunging (withholding capacity). This turns out to be the case in both surface ships and submarine vessels. Both would be implemented at levels closer to maximum technological capacity.

The move away from negative plunging in terms of surface ships helps explain the decision to build the HMS Dreadnought. Fisher, for example, claims great success for this positive plunge in a letter to King Edward in 1907:

[I]t is an absolute fact that Germany had not ... commenced building a single big ship for 18 months (Germany has been paralysed by the Dreadnought!). The more the German Admiralty looked into her qualities, the more convinced they became that they must follow suit, and the more convinced they were that the whole of their existing Battle Fleet was utterly useless. (Marder, 1956: 139-140)

The refined plunging model explains the Dreadnought decision and places it within a broader strategic context. If Britain felt more threatened and less able to rely on rapid shipbuilding to allow implementation during wartime, the Royal Navy would have to abandon negative 
plunging (withholding technology) and instead focus solely on positive plunging (implementing the highest technology possible to trump rivals' efforts). This helps to explain both Fisher's joy at HMS Dreadnought befuddling German planners, as well as subsequent historians' concerns over Britain holding nothing back vis-à-vis its rivals.

Beyond the Dreadnought decision, can the model also predict change in Britain's submarine policy? Yes. In terms of the negative plunging in submarine warfare that had been shown in the earlier period, this policy did indeed end soon after the turn of the century. The Admiralty Secretary H. O. Arnold-Forster signaled the change in policy in a minute of February 1901:

I concur with the Naval Lords that the Controller's policy [of stifling submarine technology] was certainly the right one so long as it was possible to retard the evolution of the Submarine. But ... that is no longer possible ... [and we should] abandon our policy of discouragement and to adopt one of unostentatious progress. (Lambert, 2001: 25)

In fact, Britain's policy changed to such a degree that they began to build a submarine fleet at least five years before the Germans, and had a considerably larger fleet of these vessels at the outbreak of the First World War (Brodie, 1943: 291-292).

Our refined plunging model, then, sheds some additional light on Britain's naval policies of the pre-World War I era. As Britain's position in the international system began to change, and her capacity to field new ship designs more quickly than its rivals began to diminish, then the policy of withholding technology to prevent diffusion became less tenable. After the rise of the German threat, the direct effects of implemented technology (positive plunging) outweighed the indirect effect of withheld technological capacity (negative plunging) because of an increased threat environment and increasing capacity in German shipbuilding. These results help explain Britain's notorious decision to build HMS Dreadnought and to change its long-standing submarine policy.

\section{CONCLUSIONS}

We have refined the rough concept of plunging which had been loosely articulated by Admiral Jackie Fisher. By doing so, we have been able to logically account for controversial British naval planning decisions that have been hotly debated for over a century by historians. Here we summarize the technical results of the model, discuss its applicability to current policy, and sketch out avenues of future research.

Our model formalized the idea that an actor with a military technology advantage must consider two countervailing effects when determining implementation levels. First, there is a direct effect that increases the short-run payoff through peaceful bargaining power and increased chances of winning a war. In contrast, there is an indirect imitation effect, which decreases an actor's future expected payoff through increasing the future technological capacity and level of its rival. An actor will find it optimal to withhold technology and employ a strategy of negative plunging if the indirect imitation effect dominates the direct effect. In terms of the underlying parameters, both increased patience and increased marginal sensitivity of wartime payoffs to unimplemented technological capacity increase the benefit of negative plunging.

The refined plunging model we develop is particularly pertinent for current US defense policy. In many ways modern tactical aircraft mirror late-nineteenth-century capital ships. They are both very expensive weapons systems that are extremely sensitive to technological advances and both constitute very iconic symbols of a country's prestige and influence on the international stage. The United States military is currently in transition in its air superiority and 
ground attack aircraft. Existing systems, such as the A-10 ground attack aircraft, F-15 air superiority aircraft, and F-16 multi-purpose models have been in service for decades and are currently being replaced by the F-22 air superiority aircraft, and the family of F-35 (Joint Strike Fighter) multi-purpose models. Fierce debate continues, however, as to how many, if any, of these newer models should have been fielded (Bennett, 2008; Kosiak and Watts, 2007; Murch and Bolkcom, 2007). Our plunging model cannot resolve this debate, and yet it suggests that US planners might have considered more closely the option of withholding or strategically parsing out the technology in these new aircraft, based on consideration of the parameters laid out in the model. Future case-research could systematically apply the model to similar decisions regarding weapon systems within the context of specific foreign competitors, such as a rising China.

The refined plunging model explores the most basic strategic interactions in this context, but can fruitfully be expanded. One extension for future research would be to relax the unitary actor assumption and introduce defense industries/firms as strategic agents. Also, war occurrence, which is treated as exogenous to force structure planning decisions in the current model could be endogenized in a number of interesting ways. Finally, the distinction between weapons developed for deterrence purposes versus weapons developed for defense purposes may enter planners' calculations according to a different logic, thereby altering the results. These extensions could generate many additional insights, thereby furthering our understanding of military technology, diffusion, and strategic choice.

\section{ACKNOWLEDGEMENTS}

An earlier version of this paper was presented at the 2008 International Security Studies Section of the ISA and the International Security and Arms Control Section of the APSA (ISSS/ISAC) annual conference held in Vail, Colorado. The authors would like to thank Emily Goldman, Bob O'Connell, and John Arquilla for their helpful comments.

\section{References}

Arquilla, J. (2008) Worst Enemy: The Reluctant Transformation of the American Military. Chicago, IL: Ivan R. Dee. Bennett, J. T. (2008) F-15 replacement debate intensifies. Air Force Times, February 15, 2008.

Brodie, B. (1943) Sea Power in the Machine Age, 2nd. ed. Princeton, NJ: Princeton University Press.

Brodie, B. (1976) Technological Change, strategic doctrine, and political outcomes. In Historical Dimensions in National Security Problems, edited by K. Knorr. Lawrence, KS: University of Kansas Press, 263-306.

Evangelista, M. (1988) Innovation and the Arms Race: How the United States and the Soviet Union Develop New Military Technologies. Ithaca, NY: Cornell University Press.

Goldman, E.O. (1994) Sunken Treaties: Naval Arms Control between the Wars. University Park, PA: Pennsylvania State University Press.

Goldman, E.O. and Eliason, L.C. (eds) (2003) Diffusion of Military Technology and Ideas. Palo Alto, CA: Stanford University Press.

Kosiak, S. and Watts, B. (2007) US Fighter Modernization Plans: Near-Term Choices. Washington DC: Center for Strategic and Budgetary Assessment.

Lambert, N.A. (1995) British naval policy, 1913-1914: financial limitation and strategic revolution. Journal of Modern History 67(3) 595-626.

Lambert, N.A. (2001) The Submarine Service, 1900-1918. London: Navy Records Society.

Lambert, N.A. (2004) Transformation and technology in the Fisher era: the impact of the communications revolution. Journal of Strategic Studies 27(2) 272-297.

Marder, A.J. (1952) Fear God and Dread Nought: The Correspondence of Admiral of the Fleet Lord Fisher of Kilverstone, vol. 1. London: Jonathon Cape.

Marder, A.J. (1956) Fear God and Dread Nought: The Correspondence of Admiral of the Fleet Lord Fisher of Kilverstone, vol. 2. London: Jonathon Cape.

Marder, A.J. (1976) Anatomy of British Sea Power: A History of British Naval Policy in the Pre-Dreadnought Era, 1880-1905. New York: Octagon.

Morris, J. (1995) Fisher's Face: Or, Getting to Know the Admiral. New York: Random House. 
Murch, A. and Bolkcom, C. (2007) F-35 Lightning II Joint Strike Fighter (JSF) Program: Background, Status, and Issues. CRS Report for Congress \#RL30563.

Paarlberg, R.L. (2004) Knowledge as power: science, military dominance, and US security. International Security 29(1) 122-151.

Robertson, P. (1974) Technical education in British shipbuilding and marine engineering industries, 1863-1914. Economic History Review 27(2) 222-235.

Rosen, S.P. (1984) Winning the Next War: Innovation and the Modern Military. Ithaca, NY: Cornell University Press.

Schelling, T.C. and Halperin, M.H. (1985) Strategy and Arms Control. McLean, VA: Pergamon-Brassey's.

Schilling, W.R., Hammond, P.Y. and Snyder, G.H. (1962) Strategy, Politics, and Defense Budgets. New York: Columbia University Press.

Smith, T. (1981) The Pattern of Imperialism: The United States, Great Britain, and the Late-Industrializing World Since 1815. New York: Cambridge University Press.

Sondhaus, L. (2001) Naval Warfare, 1815-1914. New York: Routledge.

Steinberg, J. (1971) The novelle of 1908: necessities and choices in the anglo-German naval arms race. Transaction of the Royal Historical Society 21 25-43.

Stokey, N.L., Lucas R.E. and Prescott, E.C. (1989) Recursive Methods in Economic Dynamics. Cambridge, MA: Harvard University Press.

Stoll, R.J. (1992) Steaming in the dark? Rules, rivals, and the British Navy, 1860-1913. Journal of Conflict Resolution 36(2) 263-283.

Sumida, J.T. (1990) British naval administration and policy in the age of Fisher. Journal of Military History 54(1) 1-26. Sumida, J.T. (1995) Sir John Fisher and the Dreadnought: the sources of naval mythology. Journal of Military History 59(4) 619-637. 


\section{APPENDIX: PROOFS}

\section{Proof of Theorem 1}

The proof of the theorem is done in two parts. We initiate the analysis by assuming ( $\dagger$ ) and construct the unique Markov Perfect Equilibrium in the levels game (Part 1). Then, regardless of the play in the levels game, we show that all Sequential Markov Perfect Equilibrium involve the capacity play $(\dagger)$ (Part 2). These two parts together prove existence and uniqueness of the Sequential Markov Perfect Equilibrium.

\section{Part 1}

The proof of existence and uniqueness of Markov Perfect Equilibrium in levels is constructive. We show that, given $(\dagger)$, the strategy profile outline based on policy function $\hat{s}(x)$ in the statement of Theorem 1 composes the unique Markov Perfect Equilibrium of the levels game. First we establish that if $x^{i} \leq \alpha x^{j}, \hat{s}^{i}(x)=x^{i}$ is an optimal choice for state $x$ regardless the other agents action.

Lemma 1 Given ( $\dagger$ ), for all $i \in\{1,2\}$ and $j \in\{1,2\} \backslash i$ such that $x^{i} \leq \alpha x^{j}$, in any equilibria the optimal choice of actor $i$ is $\hat{\boldsymbol{s}}^{i}(x)=x^{i}$.

Proof of Lemma 1. Suppose to the contrary that there exists an equilibria such that in state $x, x^{i} \leq \alpha x^{j}$ and $\bar{s}^{i}<x^{i}$. Based on the capacity strategy rule $(\dagger)$, if $x^{i} \leq \alpha x^{j}$, then $\hat{x}^{j}\left(s^{i}, x^{j}\right)=\hat{x}^{j}\left(\alpha x^{i}\right.$, $\left.x^{j}\right)=\alpha x^{j}$. Since the levels strategies in the future are only contingent on $x$, the fact that the capacity next period is the same implies that the future payoff of selecting $s^{i}=\bar{s}^{i}$ is that same as the future payoff of selecting $s^{i}=x^{i}$. Based on assumptions 1 and 2, the current payoff of agent $i$ is increasing in $s^{i}$. Consequently, $\bar{s}^{i}<x^{i} \Rightarrow \pi^{i}\left(\bar{s}^{i}, s^{j}, x\right)<\pi^{i}\left(x^{i}, s^{j}, x\right)$. This contradicts any $\bar{s}^{i}<x^{i}$ as Markov Perfect Equilibrium strategy.

Next we establish existence and uniqueness Markov Perfect Equilibrium in levels. Since we have shown that $\hat{s}^{i}(x)=x^{i}$ is the dominant strategy for agent $i$ if $x^{i} \leq \alpha x^{j}$, it only remains to show that, given $(\dagger)$ and the play described in Lemma 1, there exists a unique $\hat{s}^{i}(x)$ for all $x^{i}>$ $\alpha x^{j}$. Notice that, given ( $\dagger$ ) and Lemma 1, we can rewrite the optimization of agent $i$ when $x^{i}>$ $\alpha x^{j}$ as a fairly standard single agent dynamic programming problem. Denote $r=s^{j}=x^{j}$, and define $\pi^{i}\left(s^{i}, r, x^{i}, r\right)=\phi^{i}\left(s^{i}, r, x^{i}\right)$ the problem can be written as:

$$
V^{i}\left(r, x^{i}\right)=\max _{s^{i} \in\left[\alpha r, x^{i}\right]}\left\{\phi^{i}\left(s^{i}, r, x^{i}\right)+\delta V^{i}\left(s^{i}, \alpha x^{i}\right)\right\}
$$

Based on assumptions 1 and $2, \phi^{i}\left(s^{i}, r, x^{i}\right)$ is continuous, bounded, and strictly concave. Further, the constraint set $\left[\alpha r, x^{i}\right]$ is compact and convex valued. Thus, we can apply results from Stokey, Lucas and Prescott (1989), which guarantee the existence and uniqueness of $V^{i}$ and a policy function $s^{i}\left(r, x^{i}\right)$ for such a problem.

Now that we have established both existence and uniqueness of the Markov Perfect Equilibrium in levels given $(\dagger)$, we provide the characterization in the Theorem 1.

Lemma 2 For all for all $i \in\{1,2\}$ and $j \in\{1,2\} \backslash i$, given ( $\dagger$ ) and $x^{i}>\alpha x^{j}$, there exists discount factors $\underline{\delta}(x)$ and $\bar{\delta}(x)$ such that $0<\underline{\delta}(x)<\bar{\delta}(x)<1$ and

$$
\hat{s}^{i}(x)=\left\{\begin{array}{cc}
\alpha x^{j} & \forall \delta \in[\bar{\delta}(x), 1) \\
\left(\alpha x^{j}, x^{i}\right) & \forall \delta \in(\underline{\delta}(x), \bar{\delta}(x)) . \\
x^{i} & \forall \delta \in(0, \underline{\delta}(x)]
\end{array}\right.
$$


Proof of Lemma 2. First, note that any strictly concave function is differentiable almost everywhere. Therefore, at any point the directional partial derivative exists. Denote by $\partial^{+} f /$ $\partial x$ and $\partial^{-} f / \partial x$, the right- and left-hand partial derivatives of $f$ in $x$, respectively. This implies the maximum is the unique solution to the following conditions:

$$
\begin{gathered}
\frac{\partial \phi^{\mathrm{i}}\left(\mathrm{s}^{\mathrm{i}}, \mathrm{r}, \mathrm{x}^{\mathrm{i}}\right)}{\partial \mathrm{s}^{\mathrm{i}}}+\delta \frac{\partial^{+} \mathrm{V}^{\mathrm{i}}\left(\mathrm{s}^{\mathrm{i}}, \alpha \mathrm{x}^{\mathrm{i}}\right)}{\partial \mathrm{s}^{\mathrm{i}}} \leq 0, \\
\frac{\partial \phi^{\mathrm{i}}\left(\mathrm{s}^{\mathrm{i}}, \mathrm{r}, \mathrm{x}^{\mathrm{i}}\right)}{\partial \mathrm{s}^{\mathrm{i}}}+\delta \frac{\partial^{-} \mathrm{V}^{\mathrm{i}}\left(\mathrm{s}^{\mathrm{i}}, \alpha \mathrm{x}^{\mathrm{i}}\right)}{\partial \mathrm{s}^{\mathrm{i}}} \geq 0 .
\end{gathered}
$$

Next we establish that $V^{i}\left(s^{i}, \alpha x^{i}\right)$ is decreasing in $s^{i}$. Note that the greater $s^{i}$, the greater the other agent's next period capacity and level, while agent $i$ 's capacity is unaffected. Now suppose to the contrary that $V^{i}\left(\tilde{s}^{i}, \alpha x^{i}\right)>V^{i}\left(s^{i}, \alpha x^{i}\right)$ for some $\tilde{s}^{i}>s^{i}$. There exists a policy for each state $\tilde{s}^{i}\left({ }^{i}, \alpha x^{i}\right)$, suppose that the agent plays this in state $\left(s^{i}, \alpha x^{i}\right)$. Since $\phi^{i}$ is decreasing in $s^{i}$, the agent will get a larger payoff than in state $\left(\tilde{s}^{i}, \alpha x^{i}\right)$. Further, the payoff from that period onward will be identical because the next state is the same $\left(\hat{s}^{i}\left(\tilde{s}^{i}, \alpha x^{i}\right), \alpha^{2} x^{i}\right)$. Therefore $V^{i}\left(\tilde{s}^{i}, \alpha x^{i}\right)<V^{i}\left(s^{i}\right.$, $\left.\alpha x^{i}\right)$, for all $\tilde{s}^{i}>s^{i}$, a contradiction.

Since $V^{i}\left(s^{i}, \alpha x^{i}\right)$ is decreasing in $s^{i}$, we know that both directional derivatives $\partial^{+} V^{i}\left(s^{i}, \alpha x^{i}\right) /$ $\partial s^{i}$ and $\partial^{-} V^{i}\left(s^{i}, \alpha x^{i}\right) / \partial s^{i}$ are always negative.

Let us now use these facts to establish the existence of $\underline{\delta}(x)$ and $\delta(x)$. Let us begin with $\underline{\delta}(x)$. First note that $\partial \phi^{i}\left(s^{i}, r, x^{i}\right) / \partial s^{i}>0$ for all $s^{i} \in\left[\alpha r, x^{i}\right]$. Therefore, at $\delta=0$, the unique policy is $\hat{s}^{i}\left(r, x^{i}\right)=x^{i}$. Now to find $\underline{\delta}(x)$, take the set of all $\delta$ such that

$$
\frac{\partial \phi^{\mathrm{i}}\left(\mathrm{x}^{\mathrm{i}}, \mathrm{r}, \mathrm{x}^{\mathrm{i}}\right)}{\partial \mathrm{s}^{\mathrm{i}}}+\delta \frac{\partial^{+} \mathrm{V}^{\mathrm{i}}\left(\mathrm{x}^{\mathrm{i}}, \alpha \mathrm{x}^{\mathrm{i}}\right)}{\partial \mathrm{s}^{\mathrm{i}}} \geq 0 .
$$

The unique maximum of this set is $\underline{\delta}(x)$. Note that this set is closed and bounded above, therefore such a maximum exists. To establish $\delta(x)$, note that for all $s^{i} \in\left[\alpha r, x^{i}\right], \partial \phi^{i}\left(s^{i}, r, x^{i}\right) / \partial s^{i}>0$ and finite, while for all $s^{i} \in\left[\alpha r, x^{i}\right], \lim _{\delta \rightarrow 1} \delta \partial^{+} V^{i}\left(s^{i}, \alpha x^{i}\right) / \partial s^{i} \rightarrow \infty$. Hence, for large enough $\delta$, the unique policy is $\hat{s}^{i}\left(r, x^{i}\right)=\alpha r$. Now to find $\delta(x)$, take the set of all $\delta$ such that

$$
\frac{\partial \phi^{i}\left(\alpha r, r, x^{i}\right)}{\partial s^{i}}+\delta \frac{\partial^{-} V^{i}\left(\alpha r, \alpha x^{i}\right)}{\partial s^{i}} \leq 0
$$

The unique minimum of this set is $\delta(x)$. Note the set of such discounts is closed and bounded below, therefore such a maximum exists.

For all $\delta \in(\underline{\delta}(x), \delta(x))$

$$
\frac{\partial \phi^{\mathrm{i}}\left(\mathrm{x}^{\mathrm{i}}, \mathrm{r}, \mathrm{x}^{\mathrm{i}}\right)}{\partial \mathrm{s}^{\mathrm{i}}}+\delta \frac{\partial^{+} \mathrm{V}^{\mathrm{i}}\left(\mathrm{x}^{\mathrm{i}}, \alpha \mathrm{x}^{\mathrm{i}}\right)}{\partial \mathrm{s}^{\mathrm{i}}}>0,
$$

and

$$
\frac{\partial \phi^{i}\left(\alpha r, r, x^{i}\right)}{\partial s^{i}}+\delta \frac{\partial^{-} V^{i}\left(\alpha r, \alpha x^{i}\right)}{\partial s^{i}}>0,
$$

therefore the unique maximum is in the interior of $\left(\alpha r, x^{i}\right)$.

Part 2

In this part of the proof, we establish that all Sequential Markov Perfect Equilibria must include capacity play that follows $(\dagger)$. 


\section{Lemma 3 All Sequential Markov Perfect Equilibria involve maximum capacity $(\dagger)$.}

Proof of Lemma 3. Suppose that there exists a sequential Markov Perfect Equilibrium without $(\dagger)$. Say in state $(s, x)$ agent $i$ implements $\tilde{x}^{i}<\max x^{i}(s, x)$. Then consider a defection for agent $i$ to $\max x^{i}(s, x)$. Agent $i$ could play a levels action $\tilde{s}^{i}$ the same for the next period and agent $j$ would play the strategy as with $\tilde{x}^{i}$, since their strategies are never conditioned on the capacity of agent $i$. If agent $i$ continues to plays max $x^{i}(s, x)$ for all $(s, x)$ and switches to the level strategy $\sigma^{i}\left(s_{t-1}\right)=\tilde{s}^{i}\left(s_{t-1}, x_{t-1}^{i}\right)$ for all $\left(s_{t-1}, x_{t-1}\right)$. Then the relevant states $\left(s_{t}^{j}, x_{t}^{j}\right)$ for all $t$, will follow the same path if agent $j$ plays according to $\tilde{s}^{j}$ and $\tilde{x}^{i}$. Further, any defection by agent $j$ will illicit the identical response by agent $i$ as with play $\tilde{s}^{j}$ and $\tilde{x}^{i}$. Therefore based on assumption 3, the first order optimality conditions are unaffected by the change in agent $i$ 's capacity. Therefore, agent $j$ will still find $\tilde{s}^{j}$ and $\tilde{x}^{j}$ optimal. The result is a path with identical play for agent $j$, identical levels for agent $i$ and greater capacities in each period. Based on assumption 2, the payoff of agent $i$ is greater in each period with the maximal capacity strategy than without. Since the total payoff is a weighted sum of these per-period payoffs, the total payoff must also be greater.

\section{Comparative Statics}

Proof of Theorem 2. Suppose to the contrary that $\hat{s}^{i^{\prime}}>\hat{s}^{i}$ for some $\delta, \delta^{\prime} \in(\underline{\delta}(x), \delta(x))$ such that $\delta^{\prime}>\delta$. Then at $\hat{s}$ and $\delta$,

$$
\begin{gathered}
\frac{\partial \phi^{\mathrm{i}}\left(\hat{\mathrm{s}}^{\mathrm{i}}, \mathrm{r}, \mathrm{x}^{\mathrm{i}}\right)}{\partial \mathrm{s}^{\mathrm{i}}}+\delta \frac{\partial^{+} \mathrm{V}^{\mathrm{i}}\left(\hat{\mathrm{s}}^{\mathrm{i}}, \alpha \mathrm{x}^{\mathrm{i}}\right)}{\partial \mathrm{s}^{\mathrm{i}}} \leq 0, \\
\frac{\partial \phi^{\mathrm{i}}\left(\hat{\mathrm{s}}^{\mathrm{i}}, \mathrm{r}, \mathrm{x}^{\mathrm{i}}\right)}{\partial \mathrm{s}^{\mathrm{i}}}+\delta \frac{\partial^{-} \mathrm{V}^{\mathrm{i}}\left(\hat{\mathrm{s}}^{\mathrm{i}}, \alpha \mathrm{x}^{\mathrm{i}}\right)}{\partial \mathrm{s}^{\mathrm{i}}} \geq 0 .
\end{gathered}
$$

For $\delta^{\prime}>\delta$

$$
\frac{\partial \phi^{\mathrm{i}}\left(\hat{\mathrm{s}}^{\mathrm{i}}, \mathrm{r}, \mathrm{x}^{\mathrm{i}}\right)}{\partial \mathrm{s}^{\mathrm{i}}}+\delta^{\prime} \frac{\partial^{+} \mathrm{V}^{\mathrm{i}}\left(\hat{\mathrm{s}}^{\mathrm{i}}, \alpha \mathrm{x}^{\mathrm{i}}\right)}{\partial \mathrm{s}^{\mathrm{i}}}<\frac{\partial \phi^{\mathrm{i}}\left(\hat{\mathrm{s}}^{\mathrm{i}}, \mathrm{r}, \mathrm{x}^{\mathrm{i}}\right)}{\partial \mathrm{s}^{\mathrm{i}}}+\delta \frac{\partial^{+} \mathrm{V}^{\mathrm{i}}\left(\hat{\mathrm{s}}^{\mathrm{i}}, \alpha \mathrm{x}^{\mathrm{i}}\right)}{\partial \mathrm{s}^{\mathrm{i}}} \leq 0 .
$$

Therefore, if $\hat{s}^{i^{\prime}}>\hat{s}$, then it must be that

$$
\frac{\partial \phi^{\mathrm{i}}\left(\hat{\mathrm{s}}^{\mathrm{i}}, \mathrm{r}, \mathrm{x}^{\mathrm{i}}\right)}{\partial \mathrm{s}^{\mathrm{i}}}+\delta^{\prime} \frac{\partial^{-} \mathrm{V}^{\mathrm{i}}\left(\hat{\mathrm{s}}^{\mathrm{i}}, \alpha \mathrm{x}^{\mathrm{i}}\right)}{\partial \mathrm{s}^{\mathrm{i}}}<0 .
$$

Since each function is strictly concave,

$$
\frac{\partial \phi^{\mathrm{i}}\left(\hat{\mathrm{s}}^{\mathrm{i}}, \mathrm{r}, \mathrm{x}^{\mathrm{i}}\right)}{\partial \mathrm{s}^{\mathrm{i}}}+\delta^{\prime} \frac{\partial^{-} \mathrm{V}^{\mathrm{i}}\left(\hat{\mathrm{s}}^{\mathrm{i}}, \alpha \mathrm{x}^{\mathrm{i}}\right)}{\partial \mathrm{s}^{\mathrm{i}}}<\frac{\partial \phi^{\mathrm{i}}\left(\mathrm{q}, \mathrm{r}, \mathrm{x}^{\mathrm{i}}\right)}{\partial \mathrm{s}^{\mathrm{i}}}+\delta^{\prime} \frac{\partial^{-} \mathrm{V}^{\mathrm{i}}\left(\mathrm{q}, \alpha \mathrm{x}^{\mathrm{i}}\right)}{\partial \mathrm{s}^{\mathrm{i}}}
$$

for all $q>\hat{s}^{i}$. This implies that any $q>\hat{s}^{i}$ cannot be an optimal strategy, a contradiction.

Proof of Theorem 3. Suppose to the contrary that $\hat{s}^{i^{\prime}}>\hat{s}^{i}$ for some $\alpha^{\prime}>\alpha>1$ at any $\delta \in(\underline{\delta}(x)$, $(x)$ ) for $\alpha^{\prime}$ and $\alpha$. Then at $\hat{s}^{i}$ and $\alpha$, 


$$
\begin{gathered}
\frac{\partial \phi^{\mathrm{i}}\left(\hat{\mathrm{s}}^{\mathrm{i}}, \mathrm{r}, \mathrm{x}^{\mathrm{i}}\right)}{\partial \mathrm{s}^{\mathrm{i}}}+\delta \frac{\partial^{+} \mathrm{V}^{\mathrm{i}}\left(\hat{\mathrm{s}}^{\mathrm{i}}, \alpha \mathrm{x}^{\mathrm{i}}\right)}{\partial \mathrm{s}^{\mathrm{i}}} \leq 0, \\
\frac{\partial \phi^{\mathrm{i}}\left(\hat{\mathrm{s}}^{\mathrm{i}}, \mathrm{r}, \mathrm{x}^{\mathrm{i}}\right)}{\partial \mathrm{s}^{\mathrm{i}}}+\delta \frac{\partial^{-} \mathrm{V}^{\mathrm{i}}\left(\hat{\mathrm{s}}^{\mathrm{i}}, \alpha \mathrm{x}^{\mathrm{i}}\right)}{\partial \mathrm{s}^{\mathrm{i}}} \geq 0 .
\end{gathered}
$$

We write out $\partial^{+} V^{i}\left(\hat{s}, \alpha x^{i}\right) / \partial s^{i}$ and $\partial^{-} V^{i}\left(\hat{s}, \alpha x^{i}\right) / \partial s^{i}$ below

$$
\begin{gathered}
\frac{\partial^{+} V^{i}\left(\hat{s}^{i}, \alpha x^{i}\right)}{\partial s^{i}}=\sum_{s=t+1}^{\infty} \delta^{s-t}\left[\left(\frac{\partial \pi^{i}\left(\hat{s}_{s}, \hat{x}_{s}\right)}{\partial \hat{s}_{s}^{i}} \prod_{l=t+1}^{s} \frac{\partial^{+} \hat{s}_{l}^{i}}{\partial \hat{s}_{l}^{i}-1}\right)+\left(\frac{\partial \pi^{i}\left(\hat{s}_{s}, \hat{x}_{s}\right)}{\partial s_{s}^{i}}+\frac{\partial W^{i}\left(\hat{s}_{s}, \hat{x}_{s}\right)}{\partial x_{s}^{i}}\right) \alpha^{s-t}\right] \\
\frac{\partial^{-} V^{i}\left(\hat{s}^{i}, \alpha x^{i}\right)}{\partial s^{i}}=\sum_{s=t+1}^{\infty} \delta^{s-t}\left[\left(\frac{\partial \pi^{i}\left(\hat{s}_{s}, \hat{x}_{s}\right)}{\partial \hat{s}_{s}^{i}} \prod_{l=t+1}^{s} \frac{\partial^{-} \hat{s}_{l}^{i}}{\partial \hat{s}_{l-1}^{i}}\right)+\left(\frac{\partial \pi^{i}\left(\hat{s}_{s}, \hat{x}_{s}\right)}{\partial s_{s}^{i}}+\frac{\partial W^{i}\left(\hat{s}_{s}, \hat{x}_{s}\right)}{\partial x_{s}^{i}}\right) \alpha^{s-t}\right]
\end{gathered}
$$

Notice that for all $s \in\{\mathrm{t}+1, \ldots\}, \partial \pi^{\mathrm{i}}\left(\hat{\mathrm{s}}_{\mathrm{s}}, \hat{\mathrm{x}}_{\mathrm{s}}\right) / \partial \mathrm{s}_{\mathrm{s}}^{\mathrm{j}}+\partial \mathrm{W}^{\mathrm{i}}\left(\hat{\mathrm{s}}_{\mathrm{s}}, \hat{\mathrm{x}}_{\mathrm{s}}\right) / \partial \mathrm{x}_{\mathrm{s}}^{\mathrm{j}}<1$. Then at a larger $\alpha^{\prime}>\alpha$,

$$
\frac{\partial \phi^{i}\left(\hat{s}^{i}, r, x^{i}\right)}{\partial s^{i}}+\delta \frac{\partial^{+} V^{i}\left(\hat{s}^{i}, \alpha^{\prime}, x^{i}\right)}{\partial s^{i}}<\frac{\partial \phi^{i}\left(\hat{s}^{i}, r, x^{i}\right)}{\partial s^{i}}+\delta \frac{\partial^{+} V^{i}\left(\hat{s}^{i}, \alpha x^{i}\right)}{\partial s^{i}} \leq 0
$$

Therefore, if $\hat{s}^{i^{\prime}}>\hat{s}^{i}$, then it must be that

$$
\frac{\partial \phi^{\mathrm{i}}\left(\hat{\mathrm{s}}^{\mathrm{i}}, \mathrm{r}, \mathrm{x}^{\mathrm{i}}\right)}{\partial \mathrm{s}^{\mathrm{i}}}+\delta \frac{\partial^{-} \mathrm{V}^{\mathrm{i}}\left(\hat{\mathrm{s}}^{\mathrm{i}}, \alpha^{\prime}, \mathrm{x}^{\mathrm{i}}\right)}{\partial \mathrm{s}^{\mathrm{i}}}<0
$$

Since each function is strictly concave,

$$
\frac{\partial \phi^{\mathrm{i}}\left(\hat{\mathrm{s}}^{\mathrm{i}}, \mathrm{r}, \mathrm{x}^{\mathrm{i}}\right)}{\partial \mathrm{s}^{\mathrm{i}}}+\delta \frac{\partial^{-} \mathrm{V}^{\mathrm{i}}\left(\hat{\mathrm{s}}^{\mathrm{i}}, \alpha^{\prime}, \mathrm{x}^{\mathrm{i}}\right)}{\partial \mathrm{s}^{\mathrm{i}}}<\frac{\partial \phi^{\mathrm{i}}\left(\mathrm{q}, \mathrm{r}, \mathrm{x}^{\mathrm{i}}\right)}{\partial \mathrm{s}^{\mathrm{i}}}+\delta \frac{\partial^{-} \mathrm{V}^{\mathrm{i}}\left(\mathrm{q}, \alpha^{\prime} \mathrm{x}^{\mathrm{i}}\right)}{\partial \mathrm{s}^{\mathrm{i}}}
$$

for all $q>\hat{s}^{i}$. This implies that any $q>\hat{s}^{i}$ cannot be an optimal strategy, a contradiction.

Proof of Theorem 4. Suppose to the contrary that $\hat{s}^{i^{\prime}}>\hat{s}^{i}$ for some $\gamma^{\prime}>\gamma>0$ at any $\delta \in(\underline{\delta}(x)$, $(x))$ for $\gamma^{\prime}$ and $\gamma$. We can write out the first order conditions and substitute in $-\gamma$ for $\partial w^{i} / \partial x_{s}^{j}$.

$$
\begin{aligned}
& \frac{\partial^{+} V^{i}\left(\hat{\mathrm{s}}^{\mathrm{i}}, \mathrm{ax}^{\mathrm{i}}\right)}{\partial \mathrm{s}^{\mathrm{i}}}=\sum_{\mathrm{s}=\mathrm{t}+1}^{\infty} \delta^{\mathrm{s}-\mathrm{t}}\left[\left(\frac{\partial \pi^{\mathrm{i}}\left(\hat{\mathrm{s}}_{\mathrm{s}}, \hat{\mathrm{x}}_{\mathrm{s}}\right)}{\partial \hat{\mathrm{s}}_{\mathrm{s}}^{\mathrm{i}}} \prod_{1=\mathrm{t}+1}^{\mathrm{s}} \frac{\partial^{+} \hat{\mathrm{s}}_{1}^{\mathrm{i}}}{\partial \hat{\mathrm{s}}_{1-1}^{\mathrm{i}}}\right)+\left(\frac{\partial \pi^{\mathrm{i}}\left(\hat{\mathrm{s}}_{\mathrm{s}}, \hat{\mathrm{x}}_{\mathrm{s}}\right)}{\partial \mathrm{s}_{\mathrm{s}}^{\mathrm{j}}}-\gamma\right) \alpha^{\mathrm{s}-\mathrm{t}}\right], \\
& \frac{\partial^{-} \mathrm{V}^{\mathrm{i}}\left(\hat{\mathrm{s}}^{\mathrm{i}}, \alpha \mathrm{x}^{\mathrm{i}}\right)}{\partial \mathrm{s}^{\mathrm{i}}}=\sum_{\mathrm{s}=\mathrm{t}+1}^{\infty} \delta^{\mathrm{s}-\mathrm{t}}\left[\left(\frac{\partial \pi^{\mathrm{i}}\left(\hat{\mathrm{s}}_{\mathrm{s}}, \hat{\mathrm{x}}_{\mathrm{s}}\right)}{\partial \hat{\mathrm{s}}_{\mathrm{s}}^{\mathrm{i}}} \prod_{1=\mathrm{t}+1}^{\mathrm{s}} \frac{\partial^{-} \hat{\mathrm{s}}_{1}^{\mathrm{i}}}{\partial \mathrm{s}_{1-1}^{\mathrm{i}}}\right)+\left(\frac{\partial \pi^{\mathrm{i}}\left(\hat{\mathrm{s}}_{\mathrm{s}}, \hat{\mathrm{x}}_{\mathrm{s}}\right)}{\partial \mathrm{s}_{\mathrm{s}}^{\mathrm{j}}}-\gamma\right) \alpha^{\mathrm{s}-\mathrm{t}}\right] .
\end{aligned}
$$

It is immediate that, for $\gamma^{\prime}>\gamma$,

$$
\frac{\partial \phi^{i}\left(\hat{s}^{i}, r, x^{i}\right)}{\partial s^{i}}+\left.\delta \frac{\partial^{+} V^{i}\left(\hat{s}^{i}, a x^{i}\right)}{\partial s^{i}}\right|_{\left(\gamma^{\prime}\right)}<\frac{\partial \phi^{i}\left(\hat{s}^{i}, r, x^{i}\right)}{\partial s^{i}}+\left.\delta \frac{\partial^{+} V^{i}\left(\hat{s}^{i}, \alpha x^{i}\right)}{\partial s^{i}}\right|_{(\gamma)} \leq 0 .
$$

Therefore, if $\hat{s}^{i^{\prime}}>\hat{s}^{i}$, then it must be that 


$$
\frac{\partial \phi^{i}\left(\hat{s}^{i}, r, x^{i}\right)}{\partial s^{i}}+\left.\delta \frac{\partial^{-} V^{i}\left(\hat{s}^{i}, \alpha x^{i}\right)}{\partial s^{i}}\right|_{\left(\gamma^{\prime}\right)}<0 .
$$

Since each function is strictly concave,

$$
\frac{\partial \phi^{i}\left(\hat{s}^{i}, r, x^{i}\right)}{\partial s^{i}}+\left.\delta \frac{\partial^{-} V^{i}\left(\hat{s}^{i}, \alpha x^{i}\right)}{\partial s^{i}}\right|_{\left(\gamma^{\prime}\right)}<\frac{\partial \phi^{i}\left(q, r, x^{i}\right)}{\partial s^{i}}+\left.\delta \frac{\partial^{-} V^{i}\left(q, \alpha x^{i}\right)}{\partial s^{i}}\right|_{\left(\gamma^{\prime}\right)}
$$

for all $q>\hat{s}^{i}$. This implies that any $q>\hat{s}^{i}$ cannot be an optimal strategy, a contradiction. 